\title{
Decisões acerca de petições de registro de medicamentos novos, similares e genéricos no Brasil: os prazos fixados na Lei 13.411/2016 são factíveis?
}

Decisions about new and generic drugs marketing authorization applications in Brazil: are the deadlines defined by Law 13.411/2016 practicable?

Decisiones relativas a peticiones de registro de medicamentos nuevos y genéricos en Brasil: los plazos fijados en la Ley 13.411/2016 son factibles?

RESUMO. Objetivo: verificar se o tempo despendido no Brasil para emitir decisão sobre pedidos de registro de medicamentos novos, similares e genéricos atende aos novos prazos legais, considerando o enquadramento nas categorias de análise ordinária e prioritária. Métodos: mediante levantamento das petições cuja decisão da Agência Nacional de Vigilância Sanitária (ANVISA) foi publicada nos anos de 2015 e 2016, foram coletadas informações para determinação dos tempos de responsabilidade da Agência (para iniciar análise e a duração dessa) e das empresas requerentes (para envio de esclarecimentos). Resultados: o tempo praticado pela ANVISA em todos os casos ainda ultrapassa o limite legal, mas, se considerada a possibilidade de prorrogação em até um terço, apenas o grupo de medicamentos genéricos e similares analisados pelo rito ordinário estaria longe da meta. Conclusão: a duração da análise é razoável, mas o passivo de petições e o período que elas aguardam por avaliação são uns dos principais impedimentos para que a autoridade brasileira consiga cumprir os prazos, principalmente com relação aos genéricos e similares não priorizados; além disso, também será desafiador para a Agência a análise, em até 120 dias, dos processos de medicamentos novos priorizados, dado o ineditismo desses produtos e a complexidade da documentação ser maior que a dos demais medicamentos.

Palavras-chave: Tempo. Registro de Produtos. Medicamentos.

ABSTRACT. Objective: to verify if the delay in Brazil to decide about marketing authorization applications of new and generic drugs meets the new legal deadlines, according to the review type as standard or priority review. Methods: a survey was carried out of the applications for which the decision by Brazilian Health Regulatory Agency (ANVISA) was made in the years 2015 and 2016. Afterwards the information to determine the delay of Agency's responsibility (to begin analysis and the duration of this) and the delay of company's responsibility (for clarification) were collected. Results: the time practiced by ANVISA in all cases still exceeds the legal limit, but considering the possibility of extending the deadline by up to one third, only the group of generic drugs with standard assessment would be far from the goal. Conclusion: the duration of the assessment is reasonable, but the backlog of applications and the waiting period for assessment are one of the main obstacles for Brazilian authority to meet the deadlines, especially about non-prioritized generic drugs. In addition, it will also

\footnotetext{
${ }^{1}$ Especialista em Direito Sanitário pela Fundação Oswaldo Cruz de Brasília. Farmacêutico com Habilitação em Indústria pela Universidade Federal de Minas Gerais. Técnico em Regulação da Agência Nacional de Vigilância Sanitária. Brasília, Distrito Federal, Brasil. E-mail: allanmatos@hotmail.com
} 
be challenging for the Agency to assessment the prioritized new drugs applications within 120 days, given the novelty of these products and the complexity of the documentation being greater than the other drug products.

Keywords: Time. Products Registration. Drugs.

RESUMEN. Objetivo: verificar si el tiempo gastado en Brasil para emitir decisión sobre pedidos de registro de medicamentos nuevos y genéricos atiende a los nuevos plazos legales, considerando el encuadramiento en las categorías de análisis ordinario y prioritario. Métodos: mediante el levantamiento de las peticiones cuya decisión de la Agencia Brasileña de Regulación de la Salud (ANVISA) fue publicada en los años 2015 y 2016, se recolecta información para determinar los tiempos de responsabilidad de la Agencia (para iniciar el análisis y la duración de ésta) y de las empresas solicitantes (para el envío de aclaraciones). Resultados: el tiempo practicado por la ANVISA en todos los casos aún supera el límite legal, pero considerando la posibilidad de extender el plazo hasta en un tercio, sólo el grupo de medicamentos genéricos analizados por el rito ordinario estaría lejos de la meta. Conclusión: la duración del análisis es razonable, pero el pasivo de peticiones y el período que esperan por evaluación son uno de los principales impedimentos para que la autoridad brasileña consiga cumplir los plazos, principalmente con relación a los genéricos no priorizados. Además, también será desafiante para la Agencia el análisis en hasta 120 días de los procesos de medicamentos nuevos priorizados, dada la novedad de estos productos y la complejidad de la documentación ser mayor que la de los demás medicamentos.

Palabras-Ilave: Tiempo. Registro de Productos. Medicamentos.

\section{Introdução}

Antes de chegar ao mercado e estar disponível para consumo, é necessário que um medicamento tenha sua qualidade, segurança e eficácia terapêutica avaliadas pelo Estado, através do processo de registro, que é submetido à autoridade pública por uma empresa do setor farmacêutico, com atividade devidamente autorizada. Para Lucchesi (1), esse instrumento administrativo é de grande importância para a vigilância sanitária, dependendo do seu desempenho a qualidade dos produtos comercializados no país. Conforme escreve o autor: "Produtos de segurança ou eficácia duvidosas, ou dispensáveis do ponto de vista terapêutico, não devem ter acesso ao mercado porque expõem a população a riscos e/ou gastos desnecessários" (1).

De acordo com Said (2), na Lei 6.360/1976 (3) encontram-se as principais bases jurídicas para regular o setor farmacêutico no Brasil. Para a autora, nessa lei são incorporadas e atualizadas definições e estabelecidos requisitos relacionados ao controle e fiscalização de produtos sujeitos à vigilância sanitária, com abrangência de todas as fases (importação, produção, fracionamento, rotulagem e armazenamento), para que seja assegurada a identidade, atividade, qualidade, pureza e inocuidade devidas, para os usos 
indicados dos produtos. É também nessa lei (3) que está a exigência do registro desses produtos, sendo que a sua avaliação e concessão, atribuições inicialmente exclusivas do Ministério da Saúde, em 31 de dezembro de 1998 passaram a ser da competência da Agência Nacional de Vigilância Sanitária (ANVISA), uma autarquia vinculada a esse Ministério, criada nessa data (4).

A proteção da saúde coletiva tem sido, ao longo dos anos, o motivo para o estabelecimento de um número cada vez maior de requisitos legais, técnicos e administrativos (2). No processo de concessão de registro de um medicamento devem ser apresentados, por exemplo, informações e estudos referentes à forma como ele foi desenvolvido, produzido e controlado, dos insumos ao produto acabado; estudos de estabilidade a condições variáveis de temperatura e umidade para determinação do prazo de validade; estudos comparativos com o medicamento de referência (como equivalência farmacêutica, perfil de dissolução e bioequivalência), ou ensaios clínicos, no caso de medicamentos novos; além de documentos referentes à empresa requerente e aos fabricantes, como autorizações e certificado de boas práticas de fabricação (5).

Considerando a quantidade de assuntos envolvidos nos regulamentos que devem ser cumpridos pelas empresas solicitantes, constata-se a complexidade da análise da documentação para registro de medicamentos, o que requer muito conhecimento técnico do agente responsável pela avaliação (6).

Até 2016, o prazo de que a autoridade sanitária brasileira dispunha para decidir sobre os processos de registro era de, no máximo, 90 (noventa) dias, contados a partir da data do requerimento, conforme redação inicial do art. 12, § 3º, da Lei 6.360/1976 (3). Para Said (2), esse prazo era inviável na prática, sendo raros os casos de pedidos de registro de medicamentos resolvidos nesse tempo. Segundo a autora, para que houvesse algum efeito prático positivo a favor da empresa, seria necessário recorrer ao Poder Judiciário, pois nessa lei não estava definida nenhuma sanção em caso de descumprimento desse prazo.

Conforme escrevem Soares et al, a política de medicamentos genéricos iniciada em 1999 estimulou o crescimento e fortalecimento das indústrias nacionais. Com isso, houve um aumento de solicitações de registro que juntamente às deficiências de infraestrutura e de recursos humanos contribuíram para que 0 ato do registro no Brasil se tornasse um gargalo para o acesso da população aos medicamentos. (7) 
Segundo esses autores, até 2007 os processos eram analisados pela ANVISA apenas conforme a ordem cronológica de peticionamento, mas em abril desse ano entrou em vigência a Resolução-RDC 28/2007 (8), por meio da qual ficou regulamentada a priorização da análise técnica de petições de medicamentos considerados de relevância pública e em respeito aos critérios desse regulamento. Desde esse período, a maior parte da equipe técnica de registro de medicamentos se dedicou à análise dos priorizados, o que acelerou a saída desses processos da fila. Por outro lado, o passivo de petições não priorizadas foi aumentando. Em 2010 foram protocolados na Agência 796 dossiês de registro de genéricos e similares que se somou a um passivo de 800 petições acumuladas até o ano anterior. (7)

Partindo de uma amostra de 323 processos de registro de medicamentos genéricos, cuja publicação da decisão ocorreu no ano de 2010, e com o intuito de mensurar o tempo despendido pela ANVISA para proferir decisão sobre os pedidos, Soares et al. encontraram tempos medianos de 537 dias para os medicamentos não priorizados e 321 dias para os priorizados, considerando o intervalo entre o protocolo e a publicação da decisão e excluindo o tempo de responsabilidade da empresa para envio de esclarecimentos à Agência. (7)

A ANVISA, como autarquia da administração pública indireta, deve observar em seus atos o atendimento aos princípios administrativos da Constituição Brasileira de 1988 (9), caso contrário eles podem perder a validade. Segundo Lyra (6), o ato do registro de medicamentos deve seguir a legislação vigente e ser eficiente. Para a autora, mesmo que justificado pela Agência, a demora para se manifestar ao requerente além do prazo legal vai contra esses princípios. Tal argumento poderia ser utilizado em mandados de segurança para obtenção do registro, porém, neste caso prevaleceria o princípio da supremacia do interesse público, prezando a saúde coletiva em detrimento do interesse da empresa (6).

Em um estudo no qual foi avaliada a jurisprudência sobre mandados de segurança impetrados em razão do descumprimento do prazo para análise de processos de registro de medicamentos, Horta afirma:

Deve-se levar em conta que o registro de medicamento afeta a saúde pública de maneira intensa e, por vezes, indelével. Um medicamento prejudicial à saúde que conseguir o registro por causa da delonga da autoridade sanitária pode causar males indescritíveis à população, dependendo da extensão do uso. Por tais razões, por mais que se deva reprovar a conduta morosa do ente sanitário, não se pode fazer substituir o Judiciário à autoridade competente. A supremacia do interesse público, nesse caso, não permite que outra solução seja dada, por mais ilegal que seja a atitude do órgão competente para registro. (10) 
Para Moreira, a autoridade pública responsável pelo processo administrativo deve obedecer aos prazos definidos em lei para se manifestar, mas eles devem ser razoáveis e proporcionais ao caso concreto, ou seja, devem ser adequados ao ato praticado e ao volume de informações e documentos cujo exame se exige. (11)

Com a justificativa de tornar o prazo para avaliação de processos de registro de medicamentos condizente com a complexidade técnica e os benefícios clínicos, sociais e econômicos de cada produto, de modo a evitar a morosidade, mas sem que a qualidade da oferta seja comprometida, além de dar previsibilidade e transparência sobre esses processos, foi proposto pelo Senado Federal, em 10 de novembro de 2015, o Projeto de Lei do Senado (PLS) 727/2015 (12), para alteração das Leis 6.360/1976 (3) e 9.782/1999 (13). No texto inicial desse projeto foram propostos prazos máximos para avaliação desses processos, variando de 90 a 370 dias, a depender da sua classificação em uma destas três categorias: urgente, prioritária ou ordinária. Foi prevista, também, a possibilidade de uma prorrogação por um terço do tempo original e, em caso de necessidade de a Agência solicitar esclarecimentos ao requerente do registro, o prazo seria interrompido e voltaria a ser contado quando essa solicitação fosse atendida. Além dos prazos, também foi proposta a responsabilização dos servidores envolvidos, no caso de descumprimento injustificado.

Em 09 de março de 2016, o PLS 727/2015 foi objeto de uma audiência pública, realizada pela Comissão de Assuntos Sociais (CAS), que contou com a participação e contribuições tanto de representantes da ANVISA quanto do setor regulado. Com essas contribuições, o texto do PLS sofreu alterações (Emenda 3), principalmente com relação aos prazos inicialmente definidos para as decisões finais nos processos e às categorias de enquadramento da análise, que foram reduzidas para duas apenas (prioritária e ordinária), conforme metodologia que já vinha sendo adotada pela Agência (14), (15). Além disso, o texto inicial do PLS em que continha a previsão de interrupção da contagem dos prazos foi adequado para suspensão da contagem dos prazos, no caso de solicitação de esclarecimento à empresa. (12)

Cabe aqui ressaltar que interromper um prazo processual significa cortar a sua fluência, cancelando-se o tempo já decorrido e recomeçando a contagem do início. Já no caso de suspensão, a contagem do prazo continua do ponto que estava, portanto, nesse caso é computado o tempo decorrido antes da suspensão. (16) 
Em 1ํ de junho de 2016, o PLS 727/2015 foi remetido à Câmara dos Deputados, onde foi renomeado como Projeto de Lei (PL) 5.462/2016 (17). Nessa casa parlamentar houve três propostas de emendas, todas rejeitadas. Em 15 de dezembro desse ano foi aprovado o texto final que, cinco dias depois, foi enviado para sanção do Presidente da República. Por fim, em 28 de dezembro de 2016, o projeto de lei foi sancionado e convertido na Lei no 13.411/2016 (18), vigente desde 29 de março de 2017, sendo concedido o prazo máximo de um ano, contado a partir desta data, para decisão final sobre os processos já protocolados.

$\mathrm{Na}$ Tabela 1 encontra-se um comparativo dos principais pontos relacionados aos prazos para decisão final sobre os processos de concessão de registro de medicamentos, considerando a redação anterior da Lei 6.360/1976 (3), o texto inicial do PLS 727/2015 (12) e a nova redação dada a essa lei pela Lei 13.411/2016 (18).

Tabela 1. Comparação dos prazos para decisão final sobre petições de registro de medicamentos.

\begin{tabular}{|c|c|c|c|c|}
\hline & & $\begin{array}{l}\text { Lei } 6.360 / 1976 \\
\text { (até 28/03/2017) }\end{array}$ & $\begin{array}{l}\text { PLS 727/2015 } \\
\text { (texto inicial) }\end{array}$ & Lei 13.411/2016 \\
\hline Prazo por tipo de análise & $\begin{array}{l}\text { Urgente } \\
\text { Prioritária } \\
\text { Ordinária } \\
\text { Similar Nacional (C) } \\
\text { Outros produtos (D) }\end{array}$ & $\begin{array}{l}--- \\
90 \operatorname{dias}(A) \\
120 \operatorname{dias}(A) \\
90 \operatorname{dias}(A)\end{array}$ & $\begin{array}{l}90 \text { dias }(A) \\
180 \text { dias }(A) \\
370 \text { dias }(A) \\
\text { Não alterou } \\
360 \text { dias }(A)\end{array}$ & $\begin{array}{l}--- \\
120 \text { dias }(B) \\
365 \text { dias }(A) \\
\text { Não alterou } \\
90 \text { dias }(A)\end{array}$ \\
\hline $\begin{array}{l}\text { Possibilidade } \\
\text { prorrogação }\end{array}$ & & Não & Sim (até $1 / 3$ ) & Sim (até $1 / 3$ ) \\
\hline $\begin{array}{l}\text { Suspensão / interrupção da } \\
\text { contagem em caso de } \\
\text { solicitação } \\
\text { esclarecimento }\end{array}$ & & Interrupção (E) & Interrupção & Suspensão \\
\hline $\begin{array}{l}\text { Limite de solicitações de } \\
\text { esclarecimento }\end{array}$ & & Não há limite & Não há limite & 1 pedido $(F)$ \\
\hline $\begin{array}{l}\text { Responsabilidade } \\
\text { funcional em caso de } \\
\text { descumprimento }\end{array}$ & & Não & Sim & Sim \\
\hline
\end{tabular}

Fonte: elaborado por Matos AW, com base na Lei 6.360/1976 (texto vigente até 28/03/2017), no PLS $727 / 2015$ (texto inicial) e na Lei 13.411/2016.

(A) Contados a partir da data do requerimento do registro.

(B) Contados a partir da data do protocolo do pedido de priorização.

(C) Medicamento similar a ser fabricado no Brasil ou registrado e fabricado em Estado integrante do Mercado Comum do Sul (Mercosul), para efeito de sua comercialização no Brasil, devendo corresponder a similar nacional já registrado.

(D) Demais produtos sujeitos à vigilância sanitária não enquadrados como medicamentos. 
(E) A contagem é interrompida caso seja um "Similar Nacional" (C) e o prazo não pode exceder a 180 dias. Para os demais produtos não estava prevista na Lei a suspensão ou interrupção da contagem do prazo, a não ser na Resolução-RDC 204/2005 (19), na qual é permitida a interrupção.

(F) Exceto se necessárias para esclarecer ou retificar informações de solicitação anteriormente atendida pela empresa.

De acordo com a doutrina do Direito Processual Civil, o ato processual deve ser praticado em um determinado prazo, caso contrário está sujeito à preclusão temporal, ou seja, ao impedimento de manifestação posterior ou a sua anulação. Sob esse prisma, os prazos podem ser classificados em próprios e impróprios. Os prazos próprios, caso desrespeitados, implicam na preclusão do ato. Já os prazos impróprios (ou não-preclusivos) são aqueles cujo descumprimento não dispensa nem impede a manifestação posterior, podendo haver apenas sanção administrativa ou pecuniária ao agente que descumpriu. (16)

Conforme escreve Dinamarco (16), nos processos judiciais geralmente os prazos máximos concedidos às partes interessadas são preclusivos e os fixados ao agente julgador são não-preclusivos (impróprios). Para esse autor:

\footnotetext{
É natural que sejam impróprios os prazos fixados para o juiz porque ele não defende interesses pessoais no processo, mas cumpre deveres. Seria contrário à ética e ao senso-comum a definitiva dispensa de cumprimento de um dever, em razão do seu não-cumprimento no prazo. (16)
}

Aplicando esses conceitos utilizados na esfera judicial, por analogia, aos processos administrativos em geral e, em particular, aos de registro de medicamentos, os prazos fixados na lei (3) para proferir decisão sobre esses pedidos podem ser considerados nãopreclusivos (prazos impróprios), já que o seu descumprimento não implica na concessão automática do registro, pois a avaliação e manifestação da Agência Reguladora são indispensáveis, mas os agentes envolvidos na perda do prazo ficam sujeitos a sanção disciplinar. O prazo para as empresas enviarem esclarecimentos a uma Notificação de Exigência da Agência, por outro lado, pode ser considerado um prazo próprio, pois o seu descumprimento implica na preclusão temporal, ou seja, a perda do direito da empresa requerente sobre o processo de registro. De acordo com o disposto nos artigos $6^{\circ}$ e 11 da Resolução-RDC 204/2005 (19), o prazo para cumprimento de exigência é de 120 (cento e vinte) dias, improrrogáveis, e o descumprimento implica no indeferimento da petição.

Com o presente trabalho, pretende-se verificar se o tempo despendido no Brasil para publicar decisão sobre petições de registro de medicamentos novos, similares e genéricos, tanto nos ritos ordinário como prioritário, atende aos prazos definidos na Lei 6.360/1976 (3), 
a partir da nova redação dada através da Lei 13.411/2016 (18). Para isso, serão avaliados os dados referentes aos processos cuja decisão foi publicada no período de 2015 a 2016.

Com base no histórico dos tempos até então praticados pela ANVISA e o problema com o passivo da fila de petições de registro de medicamentos genéricos e similares, acredita-se que a análise pelo rito ordinário desses processos ainda não atende aos novos prazos. Já para as petições referentes a medicamentos novos, que possuem uma fila independente da de genéricos e similares, e para as petições analisadas pelo rito prioritário, espera-se que os prazos sejam atendidos.

\section{Métodos}

Desenvolveu-se um estudo exploratório, descritivo e analítico de dados, de caráter qualitativo e quantitativo, delimitado apenas aos processos de registro de medicamentos com princípios ativos sintéticos ou semissintéticos classificados como novos, similares e genéricos, excluídos os submetidos pelo procedimento simplificado previsto na ResoluçãoRDC 31/2014 (20). Por medicamento novo entende-se aquele com insumo farmacêutico ativo (IFA) não registrado no país, seus novos sais, isômeros ou mistura de isômeros, ésteres, éteres, complexos ou demais derivados igualmente não registrados (5).

A amostra foi obtida através de relatório gerado no Datavisa, um sistema de gestão documental da ANVISA, cujo acesso foi autorizado pelo gestor da Gerência de Avaliação de Tecnologia de Registro de Medicamentos Sintéticos (GRMED) e da Coordenação de Segurança Institucional (CSEGI). Foram levantadas apenas as petições cuja decisão da análise da Agência foi publicada em 2015 e 2016, período do qual se dispõe de dados consistentes e completos e que é imediatamente anterior à vigência da Lei 13.411/2016.

A fim de reduzir a dispersão dos dados e preservar o cenário mais frequente, de um total de 477 processos, foram excluídos 69 casos, considerados excepcionais. Entre os excluídos, encontram-se os processos:

a) cuja análise não foi realizada pela GRMED;

b) os analisados para atender a uma determinação judicial, o que interfere a tramitação normal do processo, pois em tais casos a análise é imediata e sem a possibilidade de emissão de exigências; 
c) os que tiveram desistência a pedido das empresas, pois não tiveram a análise técnica iniciada ou concluída;

d) os desarquivados, pois esses casos, se fossem considerados, elevariam o tempo médio de resposta das empresas e o tempo de permanência na fila, já que tiveram análise suspensa e estiveram na fila em mais de um momento;

e) os que retornaram para análise após julgamento de recurso contra um indeferimento; e

f) os que, por falha administrativa gerencial, aguardaram por um longo período para terem publicado o indeferimento devido à inobservância da falta de protocolo pelas empresas, dentro do prazo, de cumprimento de exigências ou desarquivamento.

Após esse filtro, a amostra passou a ser composta por 408 processos. Desse total, a quantidade correspondente aos que foram analisados pela Agência através do rito ordinário (não priorizado) foi: 221 de medicamentos genéricos e similares e 33 de medicamentos novos. Já a quantidade que representa os analisados pelo rito prioritário foi: 142 de medicamentos genéricos e similares e 12 de medicamentos novos.

Por meio desse levantamento e da amostra considerada, foram observados no site da ANVISA e no Datavisa, para cada processo, as tramitações entre os setores da Agência, as alterações da situação da análise e o histórico presente nos Pareceres Técnicos, para a obtenção das seguintes datas:

a) de entrada do processo na Agência;

b) da publicação da priorização da análise, quando aplicável;

c) do início da análise técnica;

d) da emissão de notificações de exigências e do cumprimento dessas;

e) do envio do Parecer Técnico à Gerência-Geral de Medicamentos (GGMED); e

f) da publicação do resultado da análise em Diário Oficial da União (DOU).

Apesar de ter sido estabelecido na Lei 13.411/2016 (18) que a contagem do prazo da categoria priorizada se daria a partir da data do protocolo do pedido de priorização, para este estudo foi considerada a contagem a partir da data da publicação da concessão da priorização, uma vez que tal pedido é passível de análise técnica e está sujeito a indeferimento, caso não atenda aos critérios do regulamento específico, de acordo com a relevância pública do medicamento. Além disso, conforme regulamento da ANVISA que tratava do tema e estava vigente até a publicação dessa lei, a prioridade da análise do 
processo de registro dava-se apenas após a avaliação do pedido de priorização e caso este atendesse aos critérios, caso contrário a análise se daria pelo rito ordinário. (14), (15)

Os dados foram consolidados e organizados em tabelas e gráficos realizados em software editor de planilhas, mais especificamente o Microsoft Excel versão 2016.

Ressalta-se que, além do Datavisa, o acesso aos Pareceres Técnicos e o uso dos dados para este estudo também foram autorizados pelos gestores da GRMED e CSEGI, mediante assinatura de termo de responsabilidade.

Para corroborar a discussão levantada neste estudo, foi realizado um breve levantamento bibliográfico de trabalhos com temas relacionados, em acervo de bibliotecas e em bases de pesquisa como Google Acadêmico, Pubmed, Scielo e Biblioteca Virtual em Saúde (BVS), utilizando os seguintes descritores de busca: "registro medicamento tempo análise"; "regulação sanitária medicamento"; "morosidade registro medicamento"; "prazo registro medicamento"; "eficiência legalidade registro medicamento"; "delay to approval drugs"; "prazos próprios e impróprios". Ademais, no site do Senado Federal e da Câmara dos Deputados, foi realizado um levantamento sobre o histórico do projeto que deu origem à Lei 13.411/2016 (18), observando-se a sua justificação, o texto original, as emendas, tramitações entre as Comissões do Congresso e os pareceres.

\section{Resultados e discussão}

Em todas as variáveis neste estudo (Tabela 2), a razão entre o desvio-padrão e a média amostral, medida estatística de dispersão relativa conhecida como coeficiente de variação (CV), foi maior que $30 \%$ e, na maioria dos casos, maior que $50 \%$, o que demonstra uma alta dispersão e heterogeneidade dos dados. Por esse motivo, a média não foi considerada uma medida de tendência central representativa e, portanto, para a análise e comparação dos resultados encontrados, optou-se pelo uso da mediana, uma medida que representa a posição central de distribuição dos dados de uma variável, divide uma série em duas partes iguais. Ao contrário da média, a mediana não sofre interferência de valores extremos. (21)

Referente aos processos de registro de medicamentos avaliados pelo rito ordinário, o tempo de responsabilidade da ANVISA para publicar a decisão foi de 1272 dias para os genéricos e similares e 394 dias para os novos, considerando a contagem a partir do protocolo da petição. Em cada um desses grupos de medicamentos, metade dos processos 
teve o tempo concentrado na faixa entre 972 e 1604 dias e entre 254 e 569 dias, respectivamente. (Gráfico 1), (Tabela 2 )

Já o tempo dos analisados pelo rito prioritário foi de 151 dias para os medicamentos genéricos e similares e 179 dias para os novos, considerando a contagem a partir da priorização da petição. Em cada um desses grupos de medicamentos, metade dos processos teve o tempo concentrado na faixa entre 99 e 301 dias e entre 141 e 253 dias, respectivamente. (Gráfico 2), (Tabela 2 )

Ressalta-se que, em ambos os casos, para a contagem do tempo foi desconsiderado o referente às empresas requerentes, que corresponde a esclarecimentos a notificações de exigência da ANVISA.

Gráfico 1. Tempo despendido pela ANVISA para decidir sobre as petições de registro de medicamentos, do rito ordinário, considerando o intervalo entre o protocolo e a publicação em DOU, tendo como referência dados dos processos publicados de 2015 a 2016.

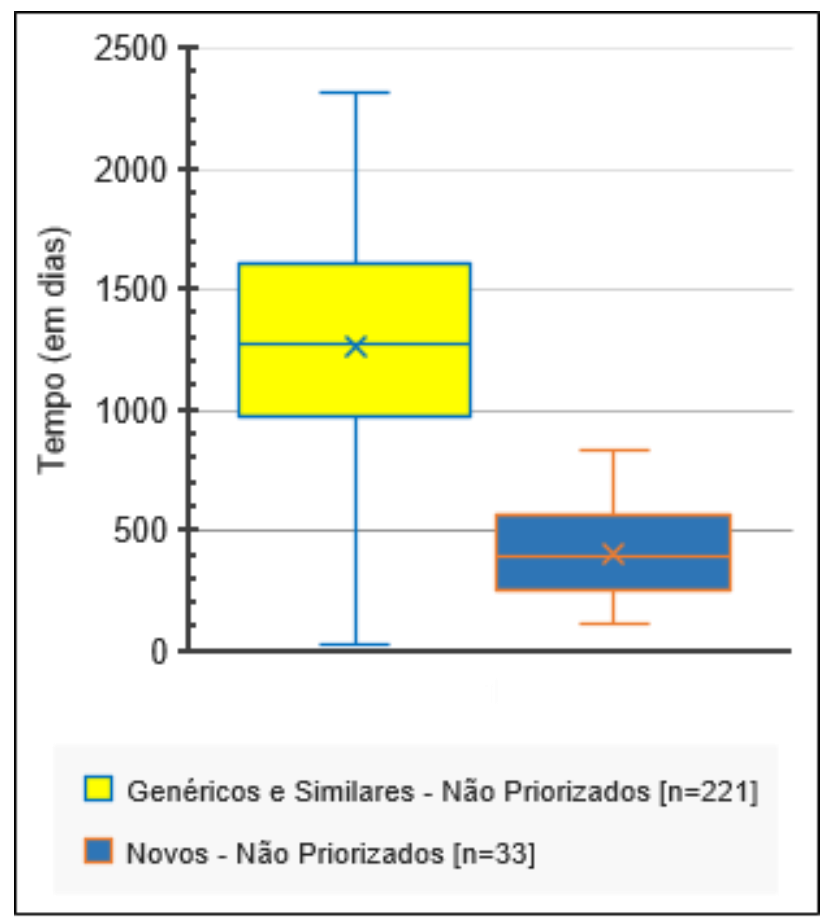

Fonte: elaborado por Matos AW, por meio de dados obtidos no Datavisa (sistema de gestão documental da ANVISA) e no histórico presente no Parecer Técnico de avaliação das petições de registro.

(n) é quantidade de processos. O tempo médio está representado pelo $X$ e a mediana é a linha que divide a caixa interquartílica.
Gráfico 2. Tempo despendido pela ANVISA para decidir sobre as petições de registro de medicamentos, do rito prioritário, considerando o intervalo entre a priorização e a publicação em DOU, tendo como referência dados dos processos publicados de 2015 a 2016.

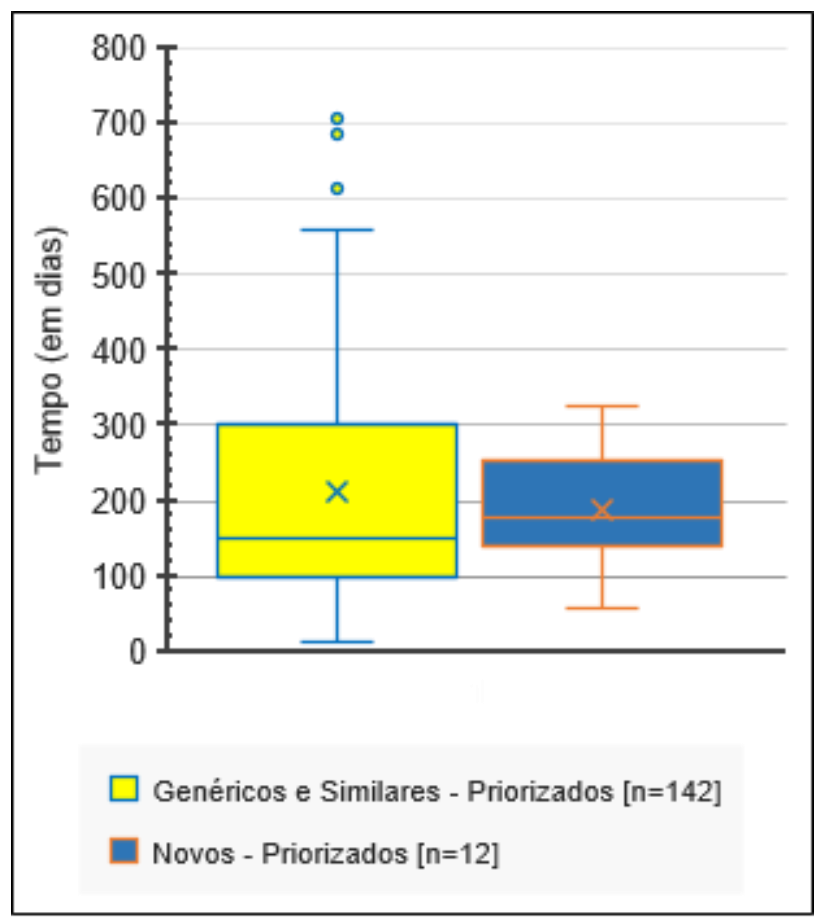

Fonte: elaborado por Matos AW, por meio de dados obtidos no Datavisa (sistema de gestão documental da ANVISA) e no histórico presente no Parecer Técnico de avaliação das petições de registro.

(n) é quantidade de processos. O tempo médio está representado pelo $X$, a mediana é a linha que divide a caixa interquartílica e os pontos discrepantes (outliers) estão representados por $\circ$. 
Considerando os prazos fixados na Lei 6.360/1976 (3) pela Lei 13.411/2016 (18), para decisão acerca dos processos de registro de medicamentos (Tabela 1), e os resultados da medida de tendência central utilizada neste estudo (mediana), observa-se que o tempo praticado pela ANVISA em todos os casos ainda ultrapassa o limite legal. No entanto, se considerada a possibilidade de prorrogação dos prazos em até um terço do prazo original, conforme ficou permitido no art. 17-A, § 5º, da Lei 6.360/1976 (3), os tempos referentes aos medicamentos novos não priorizados e aos genéricos e similares priorizados estariam dentro do limite legal; o referente aos novos priorizados estaria próximo e o tempo dos genéricos e similares avaliados pelo rito ordinário não atenderia, mesmo com a prorrogação.

Caso os novos prazos legais já estivessem vigentes na época em que foram analisadas as petições de registro de medicamento consideradas neste estudo ou se a Agência permanecer com o mesmo tempo para proferir decisão acerca desses processos, ainda que contrariando o princípio da legalidade, nesse aspecto, não há que se falar em preclusão do ato, pois tais prazos podem ser considerados impróprios para o ente da administração, cuja avaliação e manifestação são indispensáveis para a garantia da qualidade, eficácia e segurança de um medicamento a ser disponibilizado para consumo da população. Ademais, dada a relevância que o registro de um medicamento tem para a saúde coletiva e a complexidade técnica da análise desse processo administrativo, prevaleceria o princípio da supremacia do interesse público. (6), (10), (16)

Mas deve-se destacar que até a publicação da Lei 13.411/2016 (18) não havia limite sobre a quantidade de pedidos de esclarecimentos (notificações de exigência) da Agência às empresas solicitantes do registro. Se na época em que foram analisados os processos considerados neste estudo essas solicitações de esclarecimento tivessem que ser consolidadas em um único pedido, provavelmente a dispersão dos tempos ilustrados no Gráfico 1 e Gráfico 2 seria reduzida. Conforme dados apresentados na Tabela 2, a maioria dos grupos estudados apresentou mediana de 2 notificações de exigência por processo, porém a quantidade máxima chegou a 4 notificações e, no caso dos medicamentos novos não priorizados, a máxima foi de 6 .

Deve-se ponderar, ainda, que o tempo de responsabilidade da ANVISA não representa apenas o que foi despendido com análise técnica. Conforme ilustrado no Gráfico 3, a espera na fila aguardando análise representa uma parcela significativa do tempo entre o protocolo 
da petição de registro e a publicação da decisão. Nos processos analisados pelo rito ordinário (não priorizado) isso equivale a, aproximadamente, 92\% do tempo da Agência referente aos medicamentos genéricos e similares e $46 \%$ do referente aos medicamentos novos, considerando como tempo da Agência a soma dos tempos medianos de espera na fila e de análise. Se esse tempo de espera na fila fosse reduzido, os prazos poderiam ser mais facilmente cumpridos, pelo menos para os medicamentos genéricos e similares, haja vista o tempo de análise isoladamente.

Gráfico 3. Mediana dos tempos (em dias) e de quantidade de exigências referentes às petições de registro de medicamentos na ANVISA cujo resultado da análise foi publicado de 2015 a 2016.

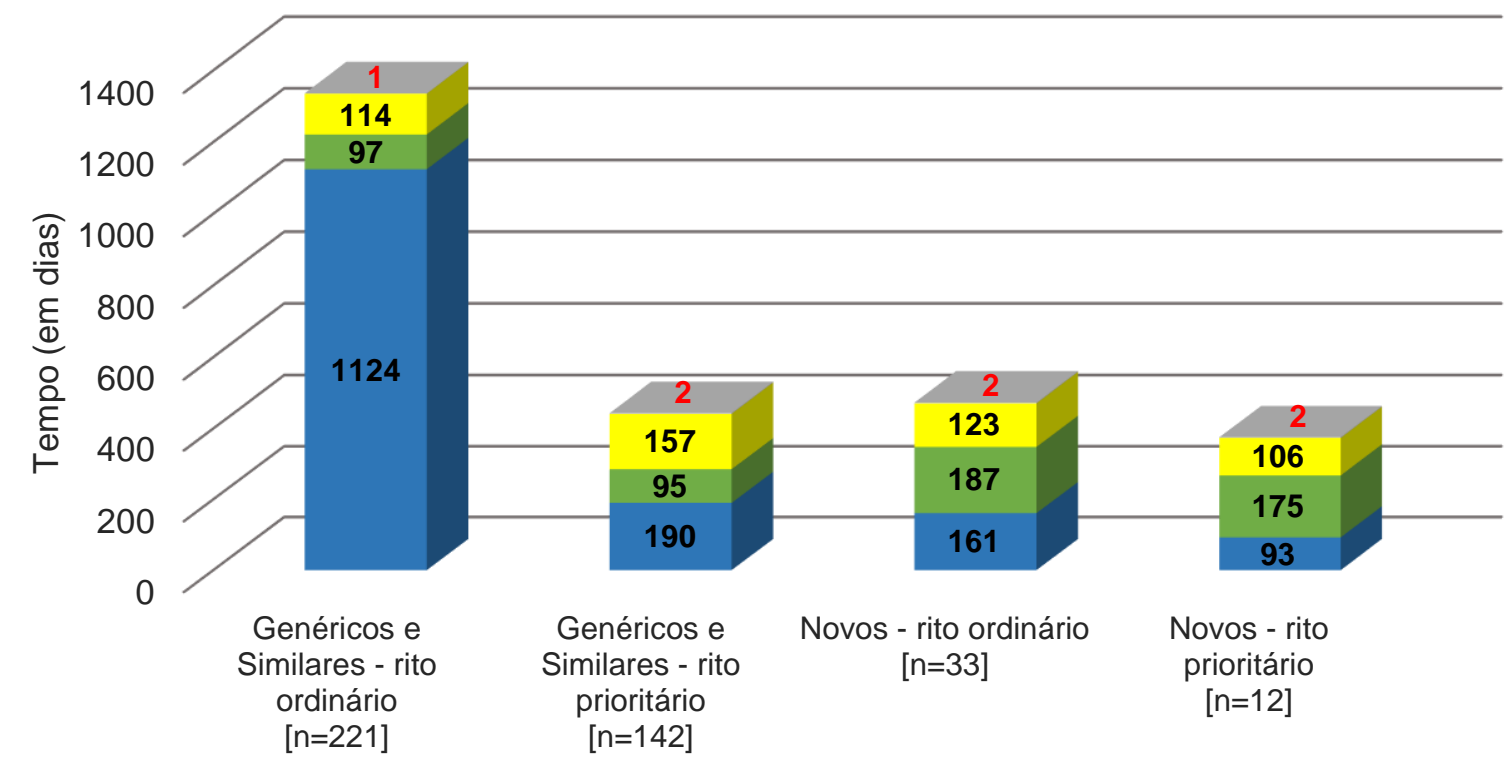

- Tempo na Fila $\square$ Tempo de análise + tramitações $\backsim$ Tempo da Empresa $\llbracket$ Quant. Exigências

Fonte: elaborado por Matos AW, por meio de dados obtidos no Datavisa (sistema de gestão documental da ANVISA) e no histórico presente no Parecer Técnico de avaliação das petições de registro.

(n) é a quantidade de processos considerados.

O tempo na fila aguardando análise apresenta-se como um dos principais obstáculos para o cumprimento dos prazos fixados para decidir sobre os processos de registro de medicamentos, principalmente para os genéricos e similares não priorizados. Esse tempo pode ser ainda mais acentuado para alguns casos, uma vez que de 2013 até o início de 2017 a fila dessas petições foi reordenada 3 vezes, perdendo uma sequência cronológica de acordo com a data em que foram protocoladas. Tal reordenamento se deu após a ANVISA 
publicar editais para que as empresas manifestassem a ordem de prioridade a ser dada a suas petições (22) ou para manifestarem interesse em desistir de algum expediente sob o benefício da migração sequencial das suas petições posteriores presentes na fila (23), (24). De acordo com Carmo (25), por exemplo, em fevereiro de 2017 havia 836 petições de registro de medicamentos genéricos e similares na fila aguardando análise, incluindo algumas protocoladas em 2010.

O impacto, ao longo do tempo, do passivo e do reordenamento da fila de petições de registro de medicamentos genéricos e similares também é evidente ao se comparar o tempo mediano de responsabilidade da Agência, entre protocolo e publicação, encontrado no presente estudo (1272 dias) (Tabela 2), referente aos processos analisados segundo rito ordinário com decisão publicada entre 2015 e 2016, e o encontrado por Soares et al (7) (537 dias), para processos cuja decisão foi publicada em 2010. Ou seja, nesse intervalo de 5 anos houve um aumento de 2,37 vezes do tempo total de responsabilidade da ANVISA.

Do resultado ilustrado no Gráfico 3, também é possível perceber uma diferença do tempo de análise entre os processos de medicamentos genéricos e similares e os processos de medicamentos novos, esses demandam quase o dobro do tempo daqueles. Essa diferença pode ser justificada pelo ineditismo desses produtos e pela maior complexidade da sua documentação, que requer maior conhecimento e estudo para avaliação. Além da documentação administrativa e técnica da qualidade, que também deve ser apresentada para o registro dos genéricos e similares, no processo de um medicamento novo ainda contém informações referentes a segurança e eficácia, como relatórios de ensaios nãoclínicos e clínicos (fases I, II e III) além de plano ou relatório de farmacovigilância. (5)

Apesar de o tempo gasto pela ANVISA para analisar medicamentos novos ser superior ao dos genéricos e similares, ele não deixa a desejar se comparado com o que é praticado por autoridades internacionais como, por exemplo, a Agência da União Europeia (European Medicines Agency - EMA). De acordo com estudo realizado por Bujar, McAuslane e Liberti (26), a Agência Europeia obteve tempos medianos de 251 e 182 dias, nas modalidades de análise padrão e priorizada (acelerada) respectivamente, para analisar pedidos de registro de medicamentos contendo novas substâncias ativas (sigla inglesa NAS), considerando os processos cuja decisão ocorreu no período entre 2012 e 2016 e excluindo o tempo de responsabilidade das empresas requerentes. Ainda segundo esses autores, se ao tempo da 
EMA for somado o tempo correspondente à Comissão Europeia (que é a responsável pela decisão jurídica de conceder uma autorização de introdução de um medicamento no mercado europeu), esse resultado sobe para 313 e 239 dias, respectivamente. Mas, ressalta-se que, ao contrário da ANVISA, a EMA possui programas de simplificação da análise ou da aprovação, a depender do caso, como a aprovação condicional, concedida antes de todos os estudos estarem disponíveis, inclusive quando não há dados clínicos de segurança e eficácia abrangentes sobre o medicamento. (26) 
Cuadernos iberomericanos de Derecho Sanitario

Tabela 2. Estatísticas sobre petições de registro de medicamentos genéricos, similares e novos com decisão da ANVISA publicada de 2015 a 2016.

\begin{tabular}{|c|c|c|c|c|c|c|c|c|c|}
\hline \multirow[b]{2}{*}{$\begin{array}{c}\text { Categoria da } \\
\text { Análise }\end{array}$} & \multirow[b]{2}{*}{$\begin{array}{c}\text { Petições de } \\
\text { Registro }\end{array}$} & \multirow[b]{2}{*}{$\begin{array}{l}\text { Medida } \\
\text { Estatística }\end{array}$} & \multicolumn{6}{|c|}{ Tempo (em dias) } & \multirow[b]{2}{*}{$\begin{array}{c}\text { Quantidade } \\
\text { de } \\
\text { Exigências }\end{array}$} \\
\hline & & & Na Fila & $\begin{array}{c}\text { Em Análise + } \\
\text { Tramitações }\end{array}$ & Da Empresa & $\begin{array}{c}\text { Entre Priorização e } \\
\text { Publicação } \\
\text { (exceto T. Empresa) }\end{array}$ & $\begin{array}{c}\text { Entre Protocolo e } \\
\text { Publicação } \\
\text { (exceto T. Empresa) }\end{array}$ & $\begin{array}{c}\text { Entre Protocolo e } \\
\text { Publicação) } \\
\text { (inclui T. Empresa) }\end{array}$ & \\
\hline \multirow[t]{14}{*}{ Ordinária } & Genéricos e & mínimo & 6 & 7 & 0 & N/A & 27 & 27 & 0 \\
\hline & Similares & 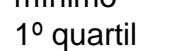 & 827 & 51 & 0 & $\mathrm{~N} / \mathrm{A}$ & 972 & 1091 & 1 \\
\hline & $(n=221)$ & mediana & 1124 & 97 & 114 & $\mathrm{~N} / \mathrm{A}$ & 1272 & 1413 & 1 \\
\hline & & média & 1132 & 129 & 112 & $\mathrm{~N} / \mathrm{A}$ & 1268 & 1380 & 1 \\
\hline & & 3ํ quartil & 1449 & 152 & 171 & $\mathrm{~N} / \mathrm{A}$ & 1604 & 1736 & 2 \\
\hline & & máximo & 2204 & 1111 & 441 & $\mathrm{~N} / \mathrm{A}$ & 2316 & 2402 & 4 \\
\hline & & desvio (dp) & 441 & 137 & 95 & $\mathrm{~N} / \mathrm{A}$ & 452 & 464 & 1 \\
\hline & Novos & mínimo & 21 & 45 & 0 & $\mathrm{~N} / \mathrm{A}$ & 111 & 129 & 0 \\
\hline & $(n=33)$ & $1^{\circ}$ quartil & 88 & 104 & 72 & $\mathrm{~N} / \mathrm{A}$ & 254 & 368 & 1 \\
\hline & & mediana & 161 & 187 & 123 & $\mathrm{~N} / \mathrm{A}$ & 394 & 521 & 2 \\
\hline & & média & 185 & 224 & 145 & $\mathrm{~N} / \mathrm{A}$ & 408 & 554 & 2 \\
\hline & & $3^{\circ}$ quartil & 250 & 312 & 216 & $\mathrm{~N} / \mathrm{A}$ & 569 & 784 & 3 \\
\hline & & máximo & 459 & 590 & 416 & $\mathrm{~N} / \mathrm{A}$ & 832 & 1083 & 6 \\
\hline & & desvio (dp) & 120 & 147 & 102 & $N / A$ & 194 & 261 & 1 \\
\hline \multirow[t]{14}{*}{ Prioritária } & Genéricos e & mínimo & 27 & 11 & 0 & 14 & 82 & 82 & 0 \\
\hline & Similares & 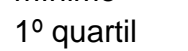 & 84 & 69 & 94 & 99 & 190 & 349 & 1 \\
\hline & $(n=142)$ & mediana & 190 & 95 & 157 & 151 & 321 & 532 & 2 \\
\hline & & média & 281 & 117 & 168 & 212 & 399 & 568 & 2 \\
\hline & & 3ํ quartil & 438 & 149 & 228 & 301 & 578 & 756 & 2 \\
\hline & & máximo & 1179 & 445 & 681 & 708 & 1288 & 1417 & 4 \\
\hline & & desvio (dp) & 249 & 71 & 109 & 157 & 260 & 293 & 1 \\
\hline & Novos & mínimo & 37 & 40 & 16 & 58 & 139 & 156 & 1 \\
\hline & $(n=12)$ & $1^{\circ}$ quartil & 54 & 140 & 63 & 141 & 223 & 280 & 2 \\
\hline & & mediana & 93 & 175 & 106 & 179 & 261 & 373 & 2 \\
\hline & & média & 118 & 173 & 124 & 187 & 291 & 415 & 2 \\
\hline & & $3^{\circ}$ quartil & 137 & 237 & 176 & 253 & 388 & 577 & 3 \\
\hline & & máximo & 306 & 274 & 329 & 325 & 462 & 722 & 4 \\
\hline & & desvio (dp) & 85 & 71 & 84 & 83 & 108 & 177 & 1 \\
\hline
\end{tabular}

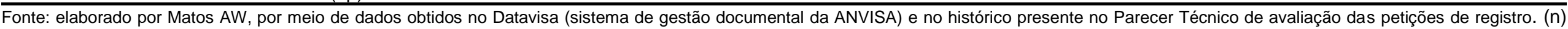
quantidade de processos considerados. (N/A) não aplicável. (dp) desvio-padrão amostral. 


\section{Conclusão}

Ainda que o tempo para decidir sobre os pedidos de registro dos medicamentos novos não priorizados e dos genéricos e similares priorizados não tenha se mostrado preocupante, a ANVISA deve manter constante monitoramento para não descumprir os prazos.

Um dos desafios será conseguir proferir decisão em até 120 dias acerca dos processos priorizados, principalmente para os medicamentos novos, haja vista o ineditismo desses produtos cuja documentação é mais complexa do que a de genéricos e similares. Mas, nesse momento, certamente um dos principais problemas para a Agência conseguir cumprir os prazos legais é o passivo de petições de registro de genéricos e similares não priorizados e, consequentemente, o tempo que elas aguardam na fila para ter a análise iniciada.

Considerando os resultados apresentados neste estudo, constata-se que o tempo restrito à análise praticado pela ANVISA para processos de registro de medicamentos novos, genéricos e similares é razoável. O tempo da Agência para medicamentos novos está inclusive alinhado com o que é praticado por autoridades internacionais, como EMA. Sendo assim, a questão do cumprimento dos prazos legais não deve ser enfrentada apenas com foco nos agentes que analisam os processos, com aumento de sua meta de produtividade, redução do tempo de análise ou flexibilização das regras para o registro. Isso seria preocupante, pois poderia implicar na liberação de medicamentos com qualidade, segurança ou eficácia duvidosas, aumentando o risco à saúde da população.

Para a redução do passivo e do tempo na fila, principalmente de petições de registro de genéricos e similares, pode ser necessário o aumento do corpo técnico, o que daria maior vazão aos processos. Outras alternativas também podem ser consideradas para 0 cumprimento dos prazos, como a possibilidade de replicar pareceres referentes a documentos semelhantes presentes em processos distintos e não vinculados formalmente, como a documentação técnica do insumo farmacêutico ativo de um fabricante em comum. Além disso, a elaboração de guias e manuais sobre estudos e documentos que compõem os processos e que apresentam alto índice de questionamento das empresas nos canais de atendimento ou que aparecem entre os motivos de indeferimento mais frequentes poderia colaborar para que fossem submetidos processos melhor instruídos, reduziria necessidade de pedidos de esclarecimento às empresas e, assim, o tempo para decisão sobre o 
processo. Outra solução, que poderia ser implementada a médio ou longo prazo, seria o uso de tecnologias para automação do controle e análise de dados dos dossiês.

\section{REFERÊNCIAS}

1. Lucchesi G. A globalização, o Mercosul e os medicamentos. Cadernos Aslegis. 1997, 1 (3): 43-50. Disponível em: http://bd.camara.gov.br/bd/handle/bdcamara/11267. [Acesso em 2.set.2017].

2. Said DMP. Registro sanitário de medicamentos: uma experiência de revisão [Dissertação]. Rio de Janeiro: Instituto Nacional de Controle de Qualidade em Saúde, Fundação Oswaldo Cruz; $2004 . \quad$ Disponível em: https://www.arca.fiocruz.br/bitstream/icict/8431/2/159.pdf. [Acesso em 2.set.2017].

3. Brasil. Lei no 6.360 , de 23 de setembro de 1976. Dispõe sobre a vigilância sanitária a que ficam sujeitos os medicamentos, as drogas, os insumos farmacêuticos e correlatos, cosméticos, saneantes e outros produtos, e dá outras providências. Brasília, 24 set 1976. Disponível em: http://www.planalto.gov.br/ccivil_03/leis/L6360.htm.[Acesso em 30.jul.2017].

4. Brasil. Medida Provisória oㅜ 1.791, de 30 de dezembro de 1998. Define o Sistema Nacional de Vigilância Sanitária, cria a Agência Nacional de Vigilância Sanitária, e dá outras providências. Brasília, 31 dez 1998. Disponível em: http://www.planalto.gov.br/ccivil_03/mpv/Antigas/1791.htm. [Acesso em 02.nov.2017]

5. Brasil. Ministério da Saúde. Agência Nacional de Vigilância Sanitária. Resolução da Diretoria Colegiada - RDC no 60, de 10 de outubro de 2014. Dispõe sobre os critérios para a concessão e renovação do registro de medicamentos com princípios ativos sintéticos e semissintéticos, classificados como novos, genéricos e similares, e dá outras providências. Brasília, 13 out 2014. Disponível em: http://portal.anvisa.gov.br/legislacao\#/visualizar/29265. [Acesso em 02.nov.2017].

6. Lyra D, Delduque MC. $O$ ato administrativo de concessão de registro de medicamentos na Agência Nacional de Vigilância Sanitária. Revista de Direito Sanitário. 2010, 10 (3): 1126. Disponível em: http://www.periodicos.usp.br/rdisan/article/view/13175/14983. [Acesso em 31.jul.2017].

7. Soares MLC, Garcia LP, Melo SRO, Rocha DB, Piras SS, Braga HA. Eficiência Regulatória: análise de sobrevivência aplicada a trajetória de registro de medicamentos 
genéricos [Texto para Discussão 1774].Brasília: Instituto de Pesquisa Econômica Aplicada. Set 2012. Disponível em: http://www.ipea.gov.br/portal/images/stories/PDFs/TDs/td_1774.pdf. [Acesso em 31.jul.2017].

8. Brasil. Ministério da Saúde. Agência Nacional de Vigilância Sanitária. Resolução da Diretoria Colegiada - RDC no 28, de 4 de abril de 2007. Dispõe sobre a priorização da análise técnica de petições, no âmbito da Gerência-Geral de Medicamentos da ANVISA, cuja relevância pública se enquadre nos termos desta Resolução. Brasília, 5 abr 2007. Disponível em: http://portal.anvisa.gov.br/legislacao\#/visualizar/27967. [Acesso em 11.out.2017].

9. Brasil. Constituição de 1988. Constituição da República Federativa do Brasil. Brasília, 5 out 1988. Disponível em: http://www.planalto.gov.br/ccivil_03/constituicao/constituicao.htm. [Acesso em 12.out.2017].

10. Horta MP. Aspectos formais sobre o registro de medicamentos e os limites da atuação judicial. Revista de Direito Sanitário. Nov 2002, 3 (3): 52-68. Disponível em: http://www.revistas.usp.br/rdisan/article/viewFile/83837/86718. [Acesso em 5.ago.2017].

11. Moreira EB. Processo administrativo: princípios constitucionais e a Lei 9.784/1999. 3 ed. São Paulo: Malheiros Editores; 2007.Princípio da legalidade (proporcionalidade, razoabilidade), 80-92.

12. Brasil. Senado Federal. Projeto de Lei do Senado o 727, de 10 de novembro de 2015. Altera as Leis $n^{\circ} 6.360$, de 23 de setembro de 1976, que dispõe sobre a vigilância sanitária a que ficam sujeitos os medicamentos, as drogas, os insumos farmacêuticos e correlatos, cosméticos, saneantes e outros produtos, e dá outras providências, e № 9.782, de 23 de janeiro de 1999, que define o Sistema Nacional de Vigilância Sanitária, cria a Agência Nacional de Vigilância Sanitária, e dá outras providências, para dar transparência e previsibilidade ao processo de concessão e renovação do registro de medicamentos e de alterações pós-registro. Brasília, 10 nov 2015. Disponível em: http://www25.senado.leg.br/web/atividade/materias/-/materia/123969. [Acesso em 5.ago.2017].

13. Brasil. Lei $n^{0}$ 9.782, de 26 de janeiro de 1999. Define o Sistema Nacional de Vigilância Sanitária, cria a Agência Nacional de Vigilância Sanitária, e dá outras providências. Brasília, 27 jan 1999. Disponível em: http://www.planalto.gov.br/ccivil_03/leis/L9782.htm. [Acesso em 2.set.2017].

14. Brasil. Ministério da Saúde. Agência Nacional de Vigilância Sanitária. Resolução da Diretoria Colegiada - RDC no 37, de 16 de junho de 2014. Dispõe sobre a priorização da análise técnica de petições de registro, pós-registro e anuência prévia em pesquisa clínica 
de medicamentos e produtos biológicos. Brasília, 18 jun 2014. Disponível em: http://portal.anvisa.gov.br/legislacao\#/visualizar/29227. [Acesso em 13.out.2017].

15. Brasil. Ministério da Saúde. Agência Nacional de Vigilância Sanitária. Instrução Normativa - IN no 3, de 16 de junho de 2014. Dispõe sobre a pontuação dos critérios para a priorização da análise técnica de petições de registro, pós-registro e anuência prévia em pesquisa clínica de medicamentos e produtos biológicos. Brasília, 18 jun 2014. Disponível em: http://portal.anvisa.gov.br/legislacao\#/visualizar/29131. [Acesso em 13.out.2017].

16. Dinamarco CR. Instituições de direito processual civil. 5 ed. São Paulo: Malheiros Editores; 2005. Vol.2, cap.51, Prazos processuais civis, 550-580.

17. Brasil. Câmara dos Deputados. Projeto de Lei $n \times 5.462$, de 01 de junho de 2016. Altera as Leis n 6.360, de 23 de setembro de 1976, que dispõe sobre a vigilância sanitária a que ficam sujeitos os medicamentos, as drogas, os insumos farmacêuticos e correlatos, cosméticos, saneantes e outros produtos, e dá outras providências, e $n^{\circ}$ 9.782, de 23 de janeiro de 1999, que define o Sistema Nacional de Vigilância Sanitária, cria a Agência Nacional de Vigilância Sanitária, e dá outras providências, para dar transparência e previsibilidade ao processo de concessão e renovação do registro de medicamentos e de alterações pós-registro. Brasília, 10 jun 2016. Disponível em: http://www.camara.gov.br/proposicoesWeb/fichadetramitacao?idProposicao=2086483. [Acesso em 2.set.2017].

18. Brasil. Lei $n=13.411$, de 28 de dezembro de 2016. Altera a Lei $n=6.360$, de 23 de setembro de 1976, que dispõe sobre a vigilância sanitária a que ficam sujeitos os medicamentos, as drogas, os insumos farmacêuticos e correlatos, cosméticos, saneantes e outros produtos, e dá outras providências, e a Lei no 9.782, de 26 de janeiro de 1999,que define o Sistema Nacional de Vigilância Sanitária, cria a Agência Nacional de Vigilância Sanitária, e dá outras providências, para dar transparência e previsibilidade ao processo de concessão e renovação de registro de medicamento e de alteração pós-registro. Brasília, 29 dez 2016. Disponível em: http://www.planalto.gov.br/ccivil_03/_ato20152018/2016/lei/L13411.htm. [Acesso em 5.ago.2017].

19. Brasil. Ministério da Saúde. Agência Nacional de Vigilância Sanitária. Resolução da Diretoria Colegiada - RDC n 204, de 6 de julho de 2005. Regulamenta o procedimento de petições submetidas à análise pelos setores técnicos da ANVISA e revoga a RDC nㅜ 349, de 3 de dezembro de 2003. Brasília, 7 jul 2005. Disponível em: http://portal.anvisa.gov.br/legislacao\#/visualizar/27559. [Acesso em 10.out.2017].

20. Brasil. Ministério da Saúde. Agência Nacional de Vigilância Sanitária. Resolução da Diretoria Colegiada - RDC no 31, de 29 de maio de 2014. Dispõe sobre o procedimento simplificado de solicitações de registro, pós-registro e renovação de registro de 
medicamentos genéricos, similares, específicos, dinamizados, fitoterápicos e biológicos e dá outras providências. Brasília, 30 maio 2014 . Disponível em: http://portal.anvisa.gov.br/legislacao\#/visualizar/29205. [Acesso em 30.jul.2017].

21. Martins GA, Domingues O. Estatística geral e aplicada. 5 ed. São Paulo: Atlas; 2014. Cap.3, Medidas descritivas, 30-65.

22. Brasil. Ministério da Saúde. Agência Nacional de Vigilância Sanitária. Edital de Notificação no 1, de 10 de abril de 2013. Brasília, 15 abr 2013. Disponível em: http://pesquisa.in.gov.br/imprensa/jsp/visualiza/index.jsp?jornal=3\&pagina $=115 \&$ data $=15 / 0$ 4/2013. [Acesso em 11.out.2017].

23. Brasil. Ministério da Saúde. Agência Nacional de Vigilância Sanitária. Edital de Requerimento de Informações $n^{\circ} 3$, de 9 de setembro de 2016. Edital para manifestação de interesse em solicitar a desistência a pedido pelas empresas com expedientes na fila de análise de registro de medicamentos similares e genéricos. Brasília, 12 set 2016. Disponível em:

http://pesquisa.in.gov.br/imprensa/jsp/visualiza/index.jsp?data=12/09/2016\&jornal=3\&pagin $\mathrm{a}=97$ \&totalArquivos=192. [Acesso em 11.out.2017].

24. Brasil. Ministério da Saúde. Agência Nacional de Vigilância Sanitária. Edital de Requerimento de Informações no 5, de 21 de dezembro de 2016. Edital para manifestação de interesse em solicitar a desistência a pedido pelas empresas com expedientes na fila de análise de registro de medicamentos similares e genéricos. Brasília, 22 dez 2016. Disponível em:

http://pesquisa.in.gov.br/imprensa/jsp/visualiza/index.jsp?data=22/12/2016\&jornal=3\&pagin $a=112 \&$ totalArquivos=220. [Acesso em 11.out.2017].

25. Carmo ACM do. Panorama de indeferimento de registro de medicamentos sintéticos em 2015 [Dissertação]. Brasília: Faculdade de Ciências da Saúde, Universidade de Brasília; 2017. Disponível em: http://repositorio.unb.br/handle/10482/24256. [Acesso em 24.set.2017].

26. Bujar M, McAuslane N, Liberti L. New drug approvals in ICH countries 2007-2016 [R\&D Briefing 62]. London: Centre for Innovation in Regulatory Science (CIRS). Apr 2017. Disponível em: http://www.cirsci.org/wp-content/uploads/2017/04/ICH-Approval-times-CIRSBriefing-62-FINAL-18042017.pdf. [Acesso em 16.ago.2017]. 
Cuadernos Iberomericanos

de Derecho Sanitario

Recebido em: 24.11.2017 Aprovado em: 26.12.2017

\section{Como citar este artigo:}

Matos AW. Decisões acerca de petições de registro de medicamentos novos, similares e genéricos no Brasil: os prazos fixados na Lei 13.411/2016 são factíveis? Revista Cadernos Ibero-Americanos de Direito Sanitário. 2017 out./dez, 6(4):147-168. 